\title{
Analysis of Vapor Absorption Refrigeration Machine Performance with Different Configuration of Water Supply
}

\author{
Anil Kumbhar1, Viveka Kaur², Dr. Sunil S. Bhagwat² \\ ${ }^{1}$ Research and Development Center Voltas Limited, Thane, Maharashtra, India \\ ${ }^{2}$ Department of Chemical Engineering, Institute of Chemical Technology, Matunga, Mumbai, Maharashtra, India

\begin{abstract}
In this article we analyzed the performance of the heat based single effect vapor absorption refrigeration machine, with the different configuration of cooling water supply. The comparison in these configuration is done on the basis of concentration of libr in the weak as well as in the strong aqueous solution, and requirement of heat load into generator also observed the percent reduction of heat load with composition of libr (XG) .all the configuration has a specific significance but we try to find out that appropriate configuration which is more economically feasible without reach the crystallization limit in the strong solution side.
\end{abstract}

KEYWORDS: vapor absorption refrigeration machine, strong solution, weak solution, generator

\section{INTRODUCTION}

To deal with the changes in global climate, rapid growth of energy demand and rapid development of renewable energy and energy utilization, much attention has been focused on the research and development (R\&D) of absorption cycles, such as absorption heat pump and absorption refrigeration cycle. In this work we try to increase the performance of vapor absorption refrigeration machine by changing the cooling water supply in three different configuration. These are as given below

Nomenclatures

\begin{tabular}{|l|l|}
\hline XG-composition of libr in at exit of generator & TC-condenser temperature \\
\hline QG-heat load at generator International & PC-condenser pressure \\
\hline XA-composition of libr in at exit of absorber & TG-Generator temperature \\
\hline COP-coefficient of performance & TGI-Inlet temp to generator \\
\hline CR-circulation ratio & TGO-Outlet temp from generator \\
\hline
\end{tabular}

CASE 1: Cooling Water Enters First Absorber and Outlet of It Goes To Condenser

In the first configuration cooling water enters first in the absorber than outlet of cooling water from absorber goes to condenser. We can see it from the fig: 1

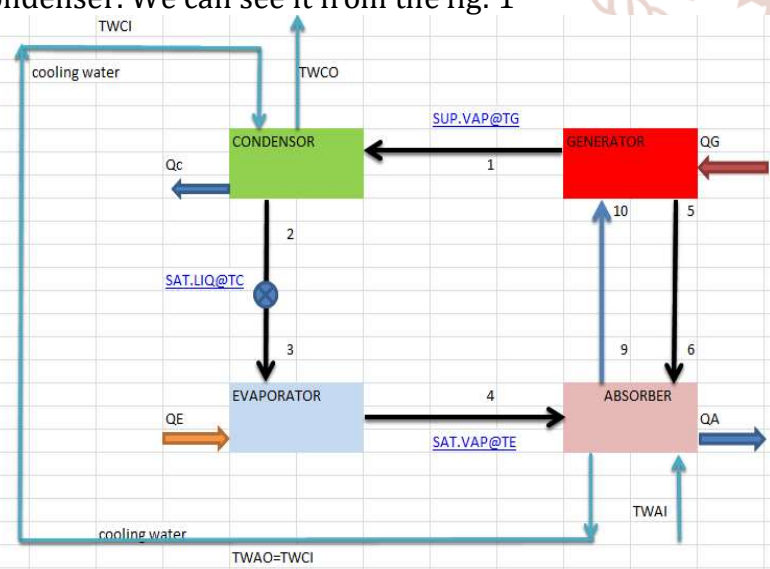

Fig: 1 cooling water enters first absorber and outlet of it goes to condenser

CASE2: Cooling Water First Enters Into Condenser and Outlet Of It Goes To Absorber

In the second configuration cooling water enters first in the condenser than outlet of it goes to the absorber. We can see it from the fig: 2 in this case TC reduced by aprox. $5 \mathrm{degC}$ but the concentration increased by approx. $3 \%$ which tends to reach near the crystallization limits. That is not desirable.

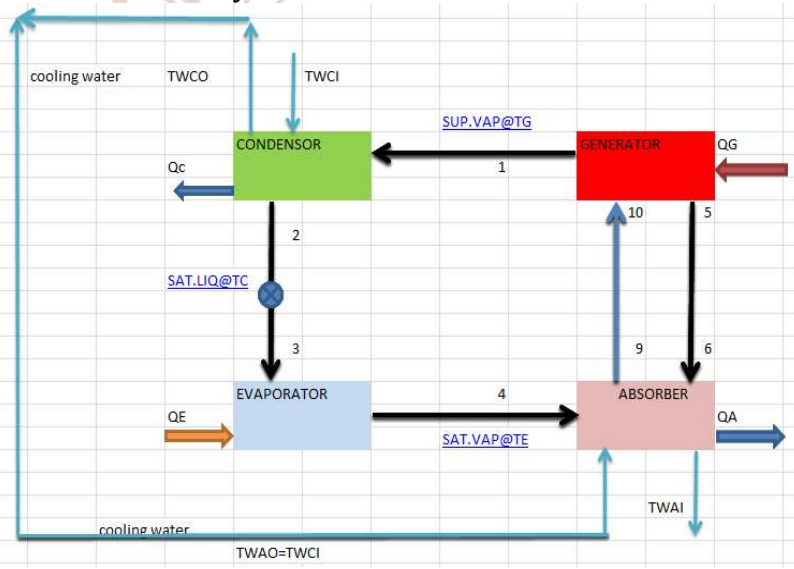

Fig:2 cooling water first enters into condenser and outlet of it goes to absorber

Case 3: Cooling Water Enters Parallel Into Absorber AND Condenser

In the third configuration cooling water enters parallely into absorber and condenser. We can see it from the fig: 3 this case shows the maximum cop among all the configuration and show less amount of heat load because the TC also go down in this case. But requirement of cooling water is almost double as compare to first and second case.so this case economically not feasible. 
International Journal of Trend in Scientific Research and Development (IJTSRD) @ www.ijtsrd.com eISSN: 2456-6470

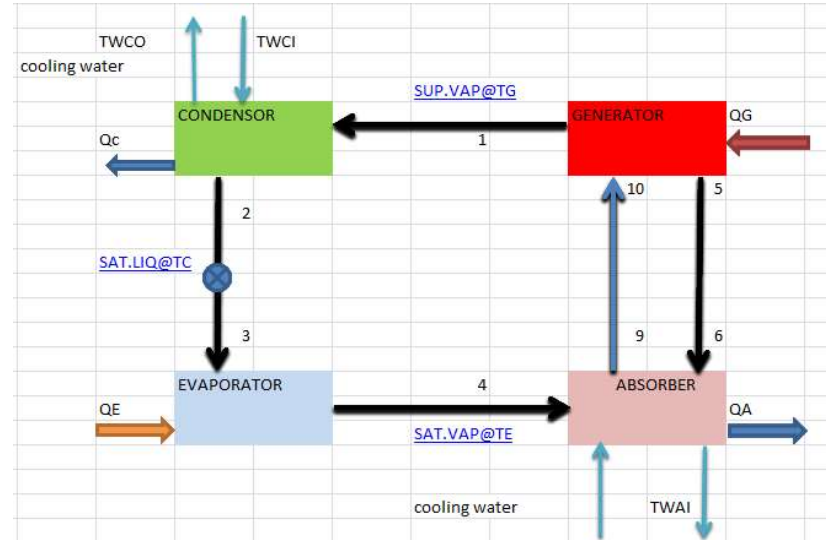

Fig:3 cooling water enters parallel into absorber and condenser

The effect of all these configurations analyzed on the basis of generator temperature, condenser pressure, absorber temperature, concentration of libr at the outlet of absorber side and generator side and also analyzed the coefficient of performance. While keeping the cooling load constant.
Third configuration shows high cop but on the verge of large supply of cooling water that is not feasible economically. While in the second configuration water enters into condenser first, this is also show the good cop but in this case we have to face large problem of crystallization means libr exceeds its solubility limit, when strong solution from generator, exchange its heat with the week solution in the solution heat exchanger. so it required rapid inspection of the system that is difficult task.

In the first configuration cop does not so high but in this configuration system can work beyond the crystallization limit and also at the low cost with respect to water supply.

This study also shows that as the temperature of condenser decease the requirement of heat source temperature reduced, so ultimately cop increased but problem of crystallization also increased. So we have to decide the optimum condition among these entire configurations. That is shown in first configuration, in which cooling water first enters absorber than condenser. The tabulated form of the out comes as given below in the table1.

Table1: observations

\begin{tabular}{|c|c|c|c|c|}
\hline Parameters & Units & case1cw in abs. & case2 cw in cond. & case3 cw in para \\
\hline TC & C & 45.9358 & 40.59363 & 40.78813 \\
\hline PC & mmhg & 75.27203 & 57.30486 & 57.89823 \\
\hline TA & C & 43.89835 & 47.74024 & 43.91214 \\
\hline XA=XGI & $\%$ & 60.3157 & 62.3967 & 60.3463 \\
\hline XGO & $\%$ & 64.6932 & 67.3967 & 64.9508 \\
\hline TGI & C & 95.20067 & 95.38219 & 92.93262 \\
\hline TGO & $\mathrm{C}$ & 103.9942 & 97.0734 & 94.43737 \\
\hline TG & $\mathrm{C}$ & 125.446 & 118.408 & 115.8632 \\
\hline QG & $\mathrm{kcal} / \mathrm{hr}$ & 1306351 & 1323973 & 1301840 \\
\hline QE & $\mathrm{kcal} / \mathrm{hr}$ & 1043280 & 1043280 & 1043280 \\
\hline $\mathrm{COP}$ & & 0.79862 & 0.787992 & 0.801389 \\
\hline $\mathrm{CR}$ & & 12.93865 & $6-6413.47933$ & 14.10608 \\
\hline
\end{tabular}

\section{VARIATION OF HEAT LOAD}

we also analyzed that amount of heat require to separate the water from the aqueous solution of libr not only depends on condenser temperature but also depends upon composition of libr because among all the above configuration if we compare first and second configuration we observed that temperature of condenser reduce when cooling water first enters into the condenser but as per the correlation[1]. it leads enhancement of concentration of libr because of this we require large heat supply in the second configuration(cooling water first enters into condenser).as we see in the graph 1 the heat load increase with increasing the composition of libr at constant TC.

\section{heat load (QG) vs XG}

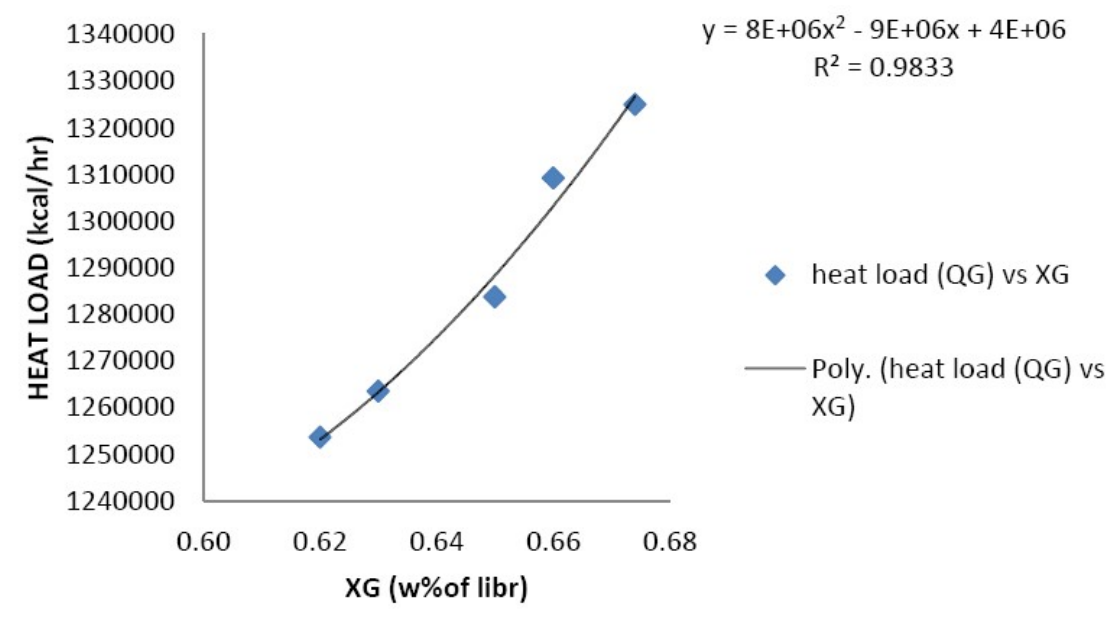

Graph:1 -variation of heat load with XG 
To see the variation of heat supply with concentration of libr at constant condenser temperature and also at constant cooling load.(the calculation part of heat load has shown in given annexure) we can observe from table 1 that as the concentration decrease requirement of heat supply also decrease . percent reduction is approximately $6 \%$ for $57 \%$ concentration of libr in generator while for $66 \%$ libr we obtained only $1.2 \%$ heat load reduction. This variation can be easily observe by the graph2. But we are unable see this variation into first and second configuration for the fix out let temperature of cooling water( from the condenser in the first case and from the absorber in the second case). if we allow to increase the concentration due to this temperature of the absorber and the condenser goes below the outlet temperature of the cooling water that is not feasible .

Table: 2 variation of heat load with concentration

\begin{tabular}{|c|c|c|c|c|c|c|c|}
\hline XG & $\begin{array}{c}\text { H1 } \\
(\mathrm{Kcal} / \mathrm{kg})\end{array}$ & $\begin{array}{c}\mathrm{H5} \\
(\mathrm{Kcal} / \mathrm{kg})\end{array}$ & $\begin{array}{c}\mathrm{H10} \\
(\mathrm{Kcal} / \mathrm{kg})\end{array}$ & $\begin{array}{c}\mathrm{m5} \\
(\mathrm{kg} / \mathrm{hr})\end{array}$ & $\begin{array}{c}\mathrm{m10} \\
(\mathrm{kg} / \mathrm{hr})\end{array}$ & $\begin{array}{c}\text { QG } \\
(\mathrm{kcal} / \mathrm{hr})\end{array}$ & \%reduction \\
\hline 0.62 & 650.79 & 264.675 & 240.59 & 23263.1 & 25127.13 & 1324846 & 0 \\
\hline 0.61 & 650.59 & 257.69 & 234.259 & 22741.18 & 24605.21 & 1309090 & 1.203 \\
\hline 0.60 & 650.11 & 252.215 & 229.85 & 22368.37 & 24232.4 & 1283608 & 3.212 \\
\hline 0.58 & 649.88 & 242.78 & 221.3022 & 21622.76 & 23486.79 & 1263402 & 4.863 \\
\hline 0.57 & 649.78 & 238.205 & 217.16 & 21249.95 & 23113.98 & 1253528 & 5.689 \\
\hline
\end{tabular}

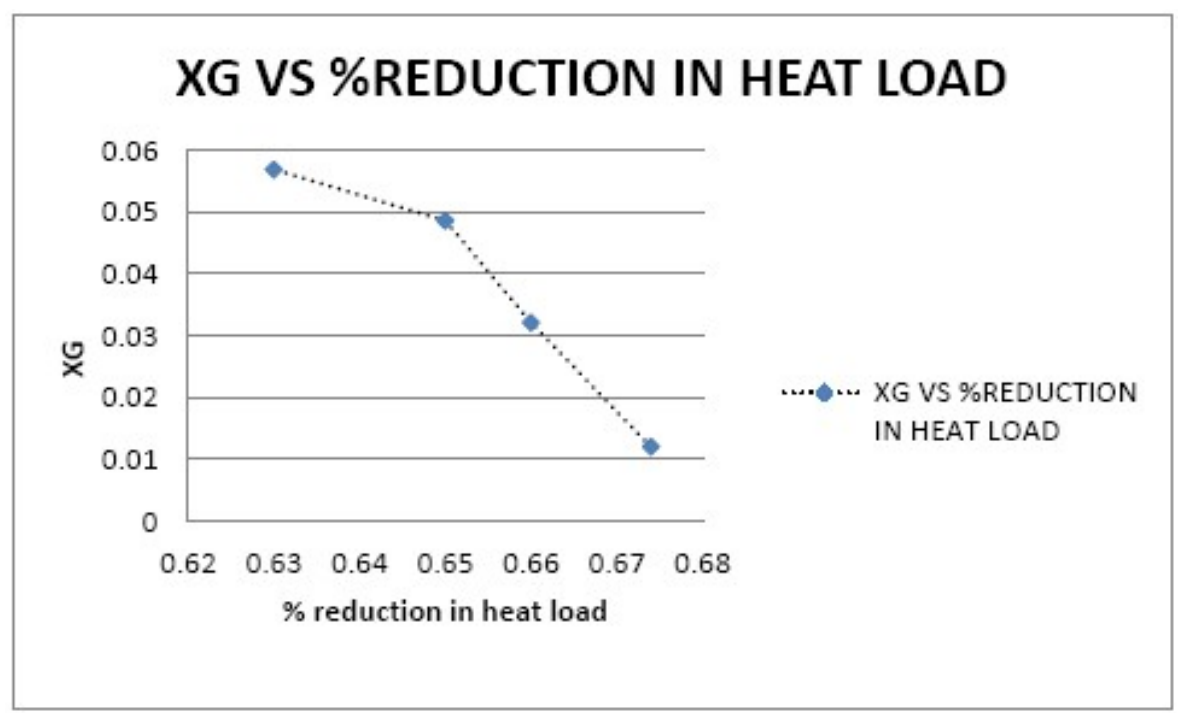

Graph: 2-variation of XG with \% reduction.

\section{CONCLUSION}

The effect of all these configurations analyzed on the basis of generator temperature, condenser pressure, absorber temperature, concentration of libr at the outlet of absorber side and generator side and also analyzed the coefficient of performance. While keeping the cooling load constant. This study also shows that as the temperature of condenser decease the requirement of heat source temperature reduced ,so ultimately cop increased but problem of crystallization also increased. So we have to decide the optimum condition among these entire configurations. That is shown in first configuration, in which cooling water first enters absorber than condenser.

we also analyzed that amount of heat require to separate the water from the aqueous solution of libr not only depends on condenser temperature but also depends upon composition of libr we can observe from table 1 that as the concentration decrease requirement of heat supply also decrease . percent reduction is approximately $6 \%$ for $57 \%$ concentration of libr in generator while for $66 \%$ libr we obtained only $1.2 \%$ heat load reduction. 


\section{Sample Calcutation}

$\stackrel{\text { Objective }}{\longrightarrow}$ Cal. Amount of heat lood require AT Given $T_{c}, Q_{\varepsilon}$

$$
\begin{aligned}
& \text { Anneware } Q_{C}=m_{4} H_{1}+m_{5} H_{5}-m_{15} H_{10}-\text { (i) } \\
& m_{r}=m_{1}=m_{4}=m_{2}=m_{3}=\text { fl-w rate of refrigerant }
\end{aligned}
$$

$\stackrel{\text { Given data }}{\longrightarrow} Q_{\varepsilon}=1043280 \mathrm{ked} / \mathrm{hr}, T_{c}=40.78 \mathrm{C}, T_{4}=116.66^{\circ} \mathrm{C}$

$$
m_{4}=\frac{Q_{\varepsilon}}{H_{4}-H_{3}} \ldots \ldots \text { (ii) }=1864.03 \mathrm{~K} / \mathrm{hr}
$$

Enthalky of set-rifir.

$$
\begin{aligned}
H_{3} & =\left(T_{\epsilon}-T_{\text {ref }}\right), H_{4}=600.4785 \frac{\mathrm{kcal}}{\mathrm{kg}} \text { at } T_{\varepsilon}\left(P_{\varepsilon}\right. \\
& =40.78 \mathrm{kell} / \mathrm{kg}
\end{aligned}
$$

Enthalpy if sup. vapor

* $H_{1}=\left(2501+1.88 * T_{n}\right) / 4.18 \ldots$ (iii)

$$
=650.79 \mathrm{keallkg}
$$

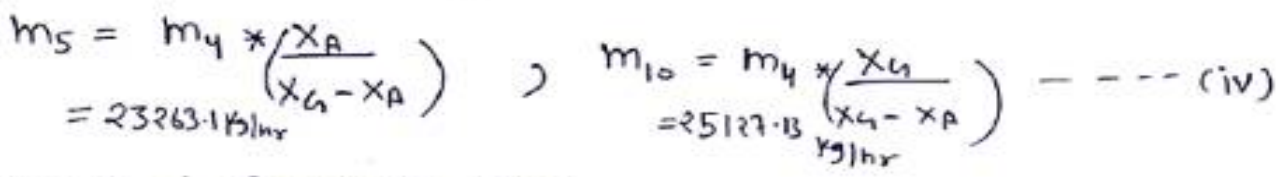

$$
\begin{aligned}
& \text { Enthalpy of Solution (2) ThO }
\end{aligned}
$$

$$
\begin{aligned}
& X_{n}=0.67, X_{A}=0.62, T_{G_{0}}=95.3137, T_{a 1}=93.65 \\
& H_{5}=. \quad \mathrm{kcal} / .
\end{aligned}
$$

* Enthalpy of solution (1) ThI

$$
\begin{aligned}
H_{10} & =42.841^{267}-425.95 \times x_{\beta}+404.67 * x_{\beta}^{2}+\left(101-1.23 x_{A}+0.42 x_{A}^{2}\right) \times T_{45} \\
& =240593 \mathrm{kcal} / \mathrm{kg} \quad(\mathrm{Vi})
\end{aligned}
$$

ofter lutting the all value in equation (i)

$$
\begin{aligned}
Q_{n} & =1864.03 * 650.79+23263.1 * 264.6751-25127.13 \times 240.593 \\
& =1324846 \mathrm{kcal} / \mathrm{hr} .
\end{aligned}
$$

REFRENCES

[1] Prof. M Ramgopal, lesson on Vapour compression refrigeration systems, version 1 ME, IIT Kharagpur (http://nptel.ac.in/courses/112105129/10) 